\title{
LAICIDAD Y DIGNIDAD DE LA FE
}

ELOY BuENo de LA Fuente1 1

DOI: https://doi.org/10.52039/seminarios.v55i192.493

El título nos introduce en la perspectiva que el autor ha elegido para presentar este trabajo: la dignidad de la fe en una cultura laica.

Y en este sentido la primera aproximación valiosa está en dos conceptos claves: laicismo y laicidad que, sin duda, el lector agradecerá la claridad y profundidad con que están tratados.

Pero además el autor nos convoca a una reflexión sobre la vocación, identidad y misión de la Iglesia. Los desafíos del presente han desenmascarado la prepotencia tanto de la Iglesia como de la utopía laica en épocas anteriores. Es hora de colaborar ante los nuevos retos de un estado que se afirma laico pero que está buscando ser referencia religiosa ante los ciudadanos.

El autor nos ofrece el regalo de una nueva dimensión de la vocación del teólogo en la actualidad. ¿Cuáles son los retos que debe afrontar? ¿Cuál será el servicio eclesial que se espera de él/ella? Desde que antropología ha de hacer este aporte a la cultura laica y al mismo diálogo en la Iglesia?

\footnotetext{
1 Eloy Bueno de la Fuente, nació en Casaseca de Campeán (Zamora). Ha realizado todos sus estudios en Burgos, donde se ordenó sacerdote. Estudios de especialización en Teología Dogmática en Burgos, y doctor en Misionología (Roma) y Filosofía (Universidad Complutense de Madrid). Actualmente da clases de Cristología y de Teoría del Conocimiento, en la Facultad de Teología de Burgos, en la que recientemente ha sido elegido Decano. Ha publicado en revistas especializadas y ha publicado diversos libros entre los que destacamos: Eclesiología, BAC, 1998; Diccionario de Misionología y animación misionera, Monte Carmelo, 2003; Diccionario del laicado y asociaciones y movimientos católicos, Monte Carmelo 2004; La Dignidad de creer, BAC, 2005.
} 
Introducción, (22); 1. Un proceso de inculturación, (24); 2. La inevitable tensión del escenario concreto, (25); 3. La fe ayuda a la laicidad con protagonismo social, (30); 4. Los protagonistas en el nuevo escenario, (32); 5. La aportación de la propia inteligibilidad, (35); 6. El laicismo y la seducción pagana, (39); 7. La fe como lógos, (43); 7.1. El Estado se sitúa en una posición ambigua o ambivalente que puede acabar en inconsciencia o en hipocresía, (43); 7.2. La ideología laicista lleva consigo una antropología, (44).

\section{INTRODUCCIÓN²}

La laicidad despliega ante nosotros el escenario cultural y político en el que se desenvuelve la vida y el testimonio de la Iglesia. Constituye una de las evidencias incuestionables en los países democráticos en general y en los occidentales en particular. Tal es su grado de evidencia que se despliega como el horizonte en el que deben moverse todos los países y culturas para lograr su pleno desarrollo, su acceso a la modernidad. La laicidad se propone como la verdadera catolicidad, como el reino de la universalidad que engloba a la humanidad entera. Ese parece ser el escenario que la Iglesia ha de habitar realizando una necesaria inculturación.

Tal evidencia sin embargo, queda empañada y oscurecida cuando, más allá de las apariencias, se considera su historia y la situación de los dos protagonistas que, de un modo u otro, han contribuido a configurarla: el estado pluralista y democrático de un lado, el cristianismo (la Iglesia Católica, fundamentalmente) de otro.

Una fuerte corriente de pensamiento fue reivindicando el espíritu laico (sustrayéndose al régimen de cristiandad) hasta dar origen a un sistema político, como estado liberal, que se afirmaba frente a las pretensiones de la Iglesia. Su forma más visible la constituyó la Ley de separación establecida en Francia en 1905. Esa separación sin embargo, debió ser modulada por respeto a la complejidad de la vida social y actualmente se ve desafiada por otras novedades que aporta el dinamismo de la sociedad.

La Iglesia se descubrió como enemiga del espíritu laico. La historia de Europa muestra una larga serie de tensiones y de incomprensiones entre los representantes eclesiales y las autoridades estatales. La Iglesia se

2 Conferencia pronunciada por el autor en el Pontificio Colegio Español san José de Roma, el 27 de marzo, 2009 en el ciclo Repensar la laicidad. España y Europa. Realidad presente y nuevas perspectivas. 
sintió acusada y por eso no siempre evitó la tentación de situarse en la trinchera. Pero también su postura debió irse modulando en función de las circunstancias. Una reconciliación, al menos a nivel de principio, se ha ido gestando lentamente, encontrando en el Vaticano II su legitimación oficial. La decisión de habitar en paz un mundo nuevo se ve también alterada por cuestiones y polémicas siempre nuevas.

La evidencia aparente esconde tensiones que nunca desaparecen, porque también ellas se van modulando en virtud del dinamismo social. La incertidumbre y el debate obligan a pensar y repensar lo que parece una evidencia. Son tres fundamentalmente los focos que deben ser tenidos en cuenta. Profundamente implicados entre ellos, merecen ser distinguidos en su peculiaridad.

a. Resulta ambiguo y equívoco el concepto. No resulta fácil un acuerdo o un consenso sobre el exacto significado de la laicidad. Signo de ello es la necesidad que muchos sienten por introducir un adjetivo que lo precise o lo adapte a las circunstancias sociales. Indicio más claro aún es la necesidad de precisar entre laicidad y laicismo. ¿En qué consiste, en consecuencia, la evidencia de que hablábamos al principio? ¿Cuál es en realidad el escenario de la inculturación de la Iglesia?

b. A esta ambigüedad de fondo hay que añadir la que genera la implicación política en la vida real de los países. Las instituciones democráticas están gestionadas por partidos políticos que propugnan ideologías diversas. Es por ello difícil que los pronunciamientos de la Iglesia no sean denunciados como voluntad de inmiscuirse en cuestiones que afectan a la sociedad civil y que deben ser discernidas exclusivamente por los representantes democráticamente elegidos. Se desemboca así fácilmente en la excomunión política de las religiones. Y es igualmente difícil que la Iglesia renuncie a valorar la realidad social desde una perspectiva que se considera superior a la política.

c. La laicidad es un producto de la historia, que se encuentra por ello en permanente movimiento. La laicidad fue inicialmente vivida por sus protagonistas y abanderados como una conquista, como un triunfo sobre poderes (entre ellos la Iglesia) que se oponían a la emancipación de los ciudadanos, soberanos y libres. Se imponía como una lucha por la dignidad humana, reclamada por la razón autónoma y crítica. ¿Cómo podía tolerar otra fuente de dignidad y de legitimación? De este modo se podía acabar en una excomunión intelectual de las religiones. 


\section{Un proceso de inculturación}

La evidencia cultural, aún en sus ambigüedades y tensiones, constituye el ambiente intelectual de la actualidad. La Iglesia se ve conducida a habitar un escenario novedoso y complejo. Ha de hacerlo desde la conciencia de su dignidad, consciente de que también defiende la dignidad del ser humano. En este nuevo y necesario esfuerzo de inculturación la fe, ayudada por la teología, debe evitar (en expresión de Jiménez Lozano) dos complejos: tanto el complejo de inferioridad como el complejo de apocalipsis.

En los tres focos que hemos mencionado la teología debe realizar un discernimiento y una contribución: para aclarar los conceptos y lo que en ellos está en juego, para saber distinguir lo urgente y lo necesario en el debate político, para analizar la dialéctica que une laicidad y laicismo.

Mirando la realidad en perspectiva histórica y valorando las corrientes de pensamiento que subyacen en el proceso cultural, centraremos nuestra exposición en la dinámica une y separa la laicidad y el laicismo. Ahí se encuentra sobre todo, a nuestro juicio, el nudo gordiano de la problemática y, en consecuencia, la óptica desde la que debe situarse la reflexión de la teología.

La laicidad es el reconocimiento de la libertad de conciencia y del pluralismo ideológico que se encuentran en la base de la democracia moderna. Ello significa que la Iglesia debe habitar un mundo que no percibe como evidente la concepción del mundo que tiene ella misma. Ese es el mundo concreto en el que la Iglesia debe modular su presencia y su aportación, legitimando su propia catolicidad. Sin complejo de inferioridad y sin complejo de apocalipsis, es decir, sin perder su protagonismo histórico y sin caer en la tentación de condenar como catastrófica la civilización en que viven tantos millones de cristianos.

La fe eclesial, cuando se hace teología, está en condiciones de afirmar su presencia y ofrecer su contribución. Esta aportación debe realizarse en una doble coordenada: consolidar actitudes que favorezcan la convivencia cuando ésta queda debilitada; enriquecer el debate colectivo con la inteligibilidad que brota de su memoria, de sus símbolos, de sus creencias. En uno y otro nivel el cristianismo puede y debe ejercer su protagonismo en la vida social. Para ello resulta imprescindible el esfuerzo de la teología. La teología ha de ayudar por tanto a los cristianos y a la Iglesia a vivir en régimen de laicidad. Estando a favor de la laicidad, se puede estar sin embargo frente al laicismo. Y no simplemente en beneficio del cristianismo sino de la misma laicidad, es decir, del conjunto de los ciudadanos, que deben convivir en sus diferencias y pluralidad. 
El laicismo cruza un umbral más allá de la laicidad: cuando el pluralismo no tolera la presencia o el protagonismo de la religión, aunque sea bajo la forma de su reclusión en el ámbito privado. En el espacio público la actitud religiosa sería un peligro porque representa una amenaza. La dignidad del ciudadano democrático debe oponerse a la religión que pretende inmiscuirse en ámbitos ajenos. En esa posición, en cuanto acusada, la fe reclama una teología capaz de defender la dignidad humana desenmascarando al fiscal, cuando éste es en realidad portavoz de la idolatría y del paganismo. Desde esa actitud, profética y alternativa, la dignidad de creer se debe presentar como defensa de la dignidad del ser humano. Contra ella atentan tanto la excomunión política como la excomunión intelectual de las religiones.

Desde el punto de vista teórico los dos ámbitos y los dos niveles pueden ser diferenciados y deben serlo en aras de la claridad intelectual y de la responsabilidad histórica de la Iglesia en nuestra civilización. No obstante este esfuerzo de clarificación debe ser consciente de la fluidez de fronteras pues la evolución de los fenómenos sociales no es controlable ni por la razón ni por la teología. Un ejemplo paradigmático lo ofrece el debate francés. Francia, considerada por muchos como una excepción, lleva tras sí una larga experiencia de laicidad, una sabiduría política para lograr puntos de consenso, una gran sensibilidad para generar reflexiones teóricas y prácticas sobre estas cuestiones, asimismo tentaciones ostensibles de opciones laicistas...

\section{La inevitable tensión del escenario concreto}

A lo largo de los últimos lustros, como veremos más adelante, han surgido en Francia voces de diversa procedencia que advierten de las debilidades de la laicidad en la civilización que efectivamente existe y que hace ver tanto las necesidades de esa sociedad como las fragilidades de la laicidad para afrontarlas. Solicitan, por tanto, una modulación de la laicidad. ¿Significa ello un retorno al clericalismo? Sensibles ante ese peligro, otros reclaman un retorno a la inspiración genuina de la laicidad. ¿No será ello una pretensión laicista? ¿No surge entonces como amenaza la excomunión política de las religiones?

Estos interrogantes surgen espontáneamente de la confrontación entre las posiciones de N. Sarkozy y J. Baubérot. Resulta iluminador este debate para comprender la imprecisión de los campos y niveles que comentábamos anteriormente. El primero, Presidente de una República laica, se convierte en portavoz de quienes reclaman una laicidad positiva. Baubérot, responsable de la primera cátedra universitaria dedicada a la 
laicidad, reacciona críticamente apelando a las esencias auténticas de la laicidad francesa.

En su toma de posesión como canónigo de la basílica de Letrán N. Sarkozy pronunció un significativo discurso que, por varias razones, constituye una novedad en la política francesa. Resuenan en él algunas ideas expresadas en el libro de entrevistas publicada en 2004 bajo el significativo título La República, las religiones y la esperanza, cuando era ministro del interior: aunque afirmaba que, desde el punto de vista político, debía situar todas las religiones en el mismo nivel, trata de superar la laicidad indiferente propugnando el retorno a una laicidad activa y no pasiva o vergonzante, desde la convicción de que la moral republicana no puede responder a todas las cuestiones ni satisfacer todas las aspiraciones ya que es insuficiente para afrontar los interrogantes fundamentales del ser humano ${ }^{3}$. A finales de 2007, en un lugar tan simbólico como la catedral del Papa y en su condición de representante de la República francesa, sus palabras tienen una nueva relevancia. Conviene reseñar con brevedad sus afirmaciones más importantes para comprender mejor las críticas que le fueron dirigidas.

a. Hay que asumir plenamente el pasado de Francia y el vínculo particular que durante tantos siglos ha unido la nación y la Iglesia. El bautismo de Clodoveo abrió un proceso histórico en virtud del cual se puede afirmar que las raíces de Francia son esencialmente cristianas.

b. Eliminar tales raíces sería perder el significado de la historia, debilitar los cimientos de la identidad nacional, secar más aún las

\footnotetext{
3 En la misma línea se debe entender y valorar las reflexiones del primer ministro Tony Blair, emitidas tras el abandono de su cargo: Para un líder político inglés hablar de su fe es siempre algo sospechoso y muy mal visto... Esto es inaceptable. No se trata de algo de lo que haya que avergonzarse. Se trata de un polo esencial de nuestra vida y deberemos poder hablar con sencillez, sin ser juzgados ridículos y reaccionarios y sin dar la impresión de poner en discusión los fundamentos del Estado laico... ¿Cómo imaginar que la fe no influye en la acción política? Es imposible. Mi fe es el punto en el que hunden sus raíces mis convicciones, sobre ella se basan los valores a los que hago referencia, la fe forja mi visión de la sociedad... El pensamiento iluminista ha querido hacer creer que el progreso imparable de la humanidad ha sido sinónimo de extinción de las religiones que se habrían hecho inútiles, que Dios estaba condenado... Sueño que se llegue a comprender que la fe no sólo es una reliquia de la historia, sino que puede tener un papel salvífico en un mundo cada vez más interdependiente.
} 
relaciones sociales, que tanta necesidad tienen de los símbolos de la memoria.

c. La mirada a la historia obliga también a reconocer que el régimen francés de la laicidad es un dato ineludible de la conciencia nacional, pues constituye la garantía de una libertad fundamental: la libertad de creer o de no creer.

d. La laicidad sigue siendo una necesidad como condición de la paz social, dado que en Francia existen personas con convicciones y creencias ideológicas diversas. El cambio de la situación a este nivel permite valorar además la laicidad como una posibilidad, como una garantía de éxito.

e. Precisamente por eso, por la relación entre Francia y el cristianismo, y por la proliferación de concepciones diversas del mundo, se requiere una laicidad positiva. Esta se conseguirá cuando se asuma que no basta que exista el maestro sino también el sacerdote y el pastor, es decir, cuando se reconozca que la aportación religiosa es imprescindible en diversas direcciones.

f. El carácter positivo de la laicidad se perfila en contraposición a la tendencia a entenderla y practicarla como voluntad de desgajar a Francia de sus raíces cristianas. Ha intentado hacerlo. Pero no hubiera debido. Como la laicidad, también las religiones deben ser valoradas como garantía de éxito y no como un peligro. Durante mucho tiempo la República ha subestimado la importancia de la aspiración espiritual del ser humano.

g. Con ello llegamos a la raíz profunda de una laicidad positiva que debe superar la situación anterior: el hecho espiritual es una tendencia natural de todos los hombres a buscar una trascendencia, pues las pequeñas esperanzas no responden a las cuestiones fundamentales del ser humano sobre el sentido de la vida y sobre el misterio de la muerte; la República tiene por ello interés en que exista una reflexión moral inspirada en convicciones religiosas, pues la moral estrictamente laica corre el riesgo de agotarse y de transformarse en fanatismo pues, al margen de la trascendencia, está más expuesta a las contingencias históricas y a los planteamientos de corto alcance.

Baubérot, desde la tradición protestante, ofreció una réplica con la publicación de un libro el año pasado con el título provocador La laïcité expliquée à M. Sarkozy. Trata de recuperar el sentido genuino de la laicidad francesa ante el riesgo que percibe en posturas como la indicada: 
a. El Presidente de la República rebasa sus competencias, pues deja de ser árbitro neutral para convertirse en portavoz de convicciones ideológicas particulares.

b. Transgredió igualmente su estatuto al intentar desarrollar un dato histórico en una dirección equivocada: el reconocimiento de la herencia histórica (ser canónigo de Letrán) debía haberse realizado sin ostentación y sin realzar su valor simbólico. La justificación que se pretende dar a ese hecho significa abolir la ley de 1905 (simbólica y moralmente, aunque no institucionalmente).

c. Se cae en el clericalismo o en la religión civil en la medida en que se pretende apelar a una referencia transcendente que abandona el nivel de lo inacabado, que es el verdadero reino de la laicidad.

d. Al solicitar una laicidad abierta se está condenando como cerrada la práctica anterior, pues los reproches del discurso presidencial se dirigen a la práctica de la laicidad, no a las religiones y a las Iglesias. La historia demuestra por el contrario que la laicidad ha sido enseñada de modo conciliador. Por ello está en condiciones de afrontar hoy también los nuevos desafíos. Para ello debe mantenerse en su nivel propio, evitando el riesgo de quedar desnaturalizada.

e. La laicidad puede quedar transformada en religión civil cuando se la refiere a una trascendencia, es decir, cuando no asume que debe mantenerse en lo inacabado, cuando no se mantiene en el nivel de aquí abajo, cuando se insiste en que el ser humano necesita una esperanza en el más allá, y se apela a un Dios desconfesionalizado. La laicidad en consecuencia prohíbe todo tipo de sacralización, también incluso el hecho social de vivir juntos.

f. La moral laica ha de ser una moral compartida, basada en principios y valores (como los derechos del hombre proclamados en 1789) y no simplemente en una comunidad de intereses. Son los individuos quienes están llamados a compartir los valores a nivel estrictamente horizontal. Ello es posible precisamente porque el Estado se declara incompetente en la cuestión de los fines últimos. Se abandonaría el terreno de la laicidad cuando se colocan las dos morales sobre el mismo plano para decretar que una es superior a la otra, y que el educador debe estar acompañado del sacerdote o del pastor.

g. La posibilidad de compartir los valores de la moral laica se produce cuando se establece una neta separación entre el reino de 
la justicia y el reino del bien, entre lo justo y lo bueno, según la teoría de Rawls. La laicidad busca reglas para la organización social según los principios de justicia, que deben ser diferenciados de los criterios que distinguen el bien y el mal. Son esas reglas de organización social las que requieren el consentimiento del conjunto del pueblo, y por tanto nadie puede definir lo justo a partir de su propia concepción del mundo. Los individuos participantes deben tomar distancia respecto a su propia concepción del bien para buscar con los otros las soluciones justas que concilien deseos antagonistas. Está es la convicción que movía ya a Ferry: buscaba una moral laica, que no tiene que ser contraria a la moral religiosa, ya que aquella es una moral horizontal, compatible con diversas opciones verticales. Desde esta perspectiva hay que criticar también a los anticlericales que se oponen a una moral laica que pretenda la convivencia entre el sacerdote y el educador (el equilibrio laico se debe lograr por tanto entre este anticlericalismo y el neoclericalismo o religión civil al estilo de la propuesta de Sarkozy).

h. Es en la vida personal o de grupo donde los ciudadanos pueden considerar los fines últimos de otro modo y con otras implicaciones. Pero lo público debe mantenerse en otro nivel, que es diferente de lo privado. No obstante reconoce que así queda planteado el terrible problema de divergencias posibles entre la cultura política pública y la cultura de grupo.

La polémica conducida por Baubérot frente a la propuesta de Sarkozy permite ver con claridad los nuevos protagonistas que han irrumpido en el escenario del debate actual: por un lado, la sensación de que las necesidades actuales reclaman la aportación de las religiones; por otro lado, la reivindicación de la laicidad como criterio superior de una moralidad pública que haga posible la convivencia democrática.

La postura de Baubérot deja ver además el terreno cargado de tensiones en el que tienen que encontrarse las religiones y la República laica: la laicidad se pretende neutra, y por ello no anticlerical, pero a la vez condena cualquier presencia pública de la religión que cuestione la tajante separación entre lo justo y lo bueno, entre la justicia (de los valores compartidos) y el bien (que implica una concepción global de la realidad). ¿Queda algún espacio posible para el protagonismo de las religiones más allá del ámbito estrictamente privado? 


\section{La fe ayuda a la laicidad con protagonismo social}

Parecería, a la luz de lo dicho, que la religión no puede justificar su presencia más que realizando acrobacias imposibles que acabarían traicionando su autoconciencia y su autoestima. No obstante existen condiciones objetivas que permiten a la fe mostrar la dignidad de su aportación, y por ello la legitimidad de su presencia desde su peculiaridad característica, desde aquello que la diferencia de la filosofía y de la política.

Ante todo, y con plena convicción (superando los dos complejos mencionados) la fe cristiana debe proclamar y asumir su obligación, como gesto de responsabilidad, para ayudar a la laicidad, a fin de que sea fiel a su propia vocación de servir a los individuos y a la convivencia social y para evitar que pierda su aliento o que cruce el umbral del laicismo, pues cualquiera de ambas salidas sería un perjuicio para la democracia misma y para la convivencia en una sociedad plural. Desde esta convicción la fe habrá de dar lo mejor de sí misma como partenaire del debate cultural en el que se juega el destino de nuestra civilización.

La laicidad, hay que tomar conciencia de ello, necesita ayuda, y esa ayuda puede provenirle de las religiones. Más aún: esta ayuda (o la mutua colaboración) se ha hecho más viable precisamente porque los antagonistas de ayer, tan prepotentes en ocasiones, han tenido que ir reconociendo su debilidad ante los desafíos del presente. Si se relativizan los fantasmas del pasado y se asume con normalidad la situación será posible avanzar hacia el futuro, una vez que los antiguos contendientes se han liberado de los condicionamientos del pasado.

La laicidad, decimos, necesita ayuda. Porque ha perdido el aliento de los orígenes y la capacidad de seducción de su madurez. El espíritu laico se fue abriendo camino como un proceso de emancipación que debía ser conquistado en una ardua batalla. Porque enfrente tenía una magnitud histórica que contaba con abundantes recursos: la Iglesia y las Iglesias que habían cobijado en su unidad de fe a los pueblos europeos.

La presión de la historia, la efervescencia de nuevas ideas, la complejidad de los procesos sociales, provocaron que el estado fuera reivindicando y asumiendo tareas y competencias que durante siglos habían quedado depositadas en las manos de la Iglesia: la actividad legisladora, la tarea educativa, la atención médica, la promoción de la ciencia...

Progresivamente el estado fue tomando conciencia de que tarea y competencia suya era la configuración y la gestión del espacio público con el fin de facilitar la convivencia y la paz entre personas que tuvieran creencias diversas: las guerras de religión hicieron ver la necesidad de una instancia unificadora que evitara los conflictos suscitados por las creencias. 
La inicial tolerancia fue paulatinamente transformándose en una noción de ciudadanía libre de presupuestos confesionales. El espacio público, garantizado y encarnado por el estado, no necesitaba más fundamento o legitimidad que los provenientes de la razón universal o del consenso entre los ciudadanos. Se había roto la conexión entre pertenencia a una nación y pertenencia a una religión: sólo la condición de individuo y de ciudadano, al margen de su concepción del mundo, es la que lo sitúa en el espacio público como miembro del estado.

En este proceso se elaboraron y se propusieron grandes palabras que resonaban con la ilusión de un proyecto histórico que conducía a una situación mejor: la libertad de conciencia y de religión iba unida al progreso, a la democracia, al desarrollo, a la emancipación, a la felicidad... Ese entramado de ideales llenaba de entusiasmo el corazón de quienes aspiraban a ser protagonistas de un futuro mejor, desvinculado de la opresión del pasado. Por eso el estado se consideraba el responsable de la educación de los ciudadanos en los valores republicanos.

Este esfuerzo de liberación y de afirmación produjo numerosos conflictos, incluso divisiones y fracturas en la vida social. No obstante el proceso tuvo que ir acomodándose a la complejidad social, y por ello se fueron buscando soluciones a los temas en debate (cultos, escuela...). Los ideales que encarnaban una moral vivida casi con pasión religiosa se fue modulando como una sabiduría práctica en aras de la paz y del equilibrio social.

Por parte de la Iglesia se fue produciendo una evolución equiparable, aunque en otra dirección. No se pueden negar las resistencias que por parte de la Iglesia se levantaron frente a un dinamismo que era valorado como enemigo y adversario. Resultaba doloroso renunciar a medios a través de los cuales -se pensaba- resultaba más eficaz y efectivo el servicio a la verdad de la revelación. No se trataba simplemente de renunciar a privilegios temporales y mundanos. Estaba en juego la dignidad de la propia identidad y misión: ¿cómo conjugar esa amplia gama de libertades, que procedían de la sociedad y del consenso de los ciudadanos, con una verdad que había sido revelada y de la cual la Iglesia se proclamaba portadora y responsable? Era a este nivel donde se jugaba la cuestión de fondo. Y si no se encontraba una salida a ese interrogante ni la Iglesia se reconciliaría con la nueva situación histórica ni podría encontrar el modo adecuado de aportar su contribución más genuina.

El concilio Vaticano II selló de modo oficial la nueva actitud de la Iglesia Católica, especialmente en su declaración sobre la libertad religiosa. A la luz de la centralidad y de la dignidad de la persona humana se conjugan los derechos de la verdad (para evitar todo tipo de relativismo o indiferentismo) y la libertad religiosa (dado que la fe no se puede imponer, 
es ilegítima toda coacción de cara a la fe). Desde el punto de vista teológico podríamos decir que la laicidad es la expresión jurídica de la libertad del acto de fe: el espacio público debe crear las condiciones para que todos los ciudadanos vivan inmunes de toda presión indebida en el nivel de las creencias y de la conciencia. Este reconocimiento supuso para la Iglesia la renuncia a legitimar el sistema político confesional aún presente en países de tradición católica.

\section{Los protagonistas en el nuevo escenario}

La evolución de las circunstancias ha hecho que ninguno de los antiguos oponentes aparezca revestido de las actitudes de combate de antaño. La laicidad dejó de ser reivindicación para convertirse en sabiduría política de lo plural. La Iglesia acaba incluyendo la laicidad como dimensión de la libertad de la fe y de su propio ser en el mundo, es decir, el escenario público laico ha de modular su acción evangelizadora.

El cambio se ha ido acentuando en otros niveles. No sólo han debido modular sus posiciones. Ambas partes han perdido fuerza y capacidad de presión. La Iglesia, en virtud de proceso de secularización, ha visto debilitarse su presencia social y su capacidad de influir en los individuos. No puede por ello ser considerada como adversario por su antiguo oponente, pues carece de recursos para alterar los valores y las estructuras democráticas. Desde este punto de vista, podríamos decir, es la parte más débil. En su debilidad sin embargo, puede aportar una contribución a una laicidad que experimenta su propia debilidad.

Son muchas las voces que expresan esta conciencia de la nueva situación. Portavoces que, aunque desde concepciones del mundo diversas, asumen los criterios y los principios de la laicidad (M. Gauchet, L. Ferry, G. Coq, P. Valadier, D. Hervieu-Leger). Recordemos brevemente los ejes en torno a los cuales giran estas reflexiones.

a. Los valores de la República laica han perdido su capacidad de encantamiento y de convocatoria de cara a crear un proyecto de futuro. La distancia respecto a la política ha penetrado sobre todo en el espíritu de las nuevas generaciones, como lo demuestra la baja cuota de afiliación a los partidos institucionales. La crisis de la misma modernidad, con el hundimiento de los mitos laicos, provoca la huída del escenario público, en el que se ha impuesto la frivolidad y la banalidad en sustitución de las grandes palabras, carentes de vitalidad y de contenido.

b. Los intereses de los individuos se concretan en la satisfacción o 
logro de los deseos inmediatos. La referencia a lo público se concentra en el estado-providencia, del cual se espera la respuesta a las expectativas inmediatas. La dinámica de la banalidad se concentra en la biopolítica, como eje en torno a la cual giran las reclamaciones de los individuos, que son votantes y por ello condicionan las ofertas de las organizaciones políticas. Al quedar el individuo sin referencias colectivas se fomenta el egocentrismo, que es el germen del egoísmo y de la insolidaridad.

c. Ante el anonimato que acaba dominando el escenario público los individuos, en su debilidad y carencia, buscan el refugio del grupo que le ofrece apoyo y cobijo. Por ello se desarrollan los comunitarismos, considerados como alternativa al espíritu vacío de la laicidad pública. Los comunitarismos pueden ser el caldo de cultivo de violencia, cuando se dan las condiciones sociales y económicas que la fomentan. Incluso algunos detectan pequeños pasos hacia la barbarie, con amenazas de procedencias diversas. Paradójicamente, contra lo esperado por sus promotores, la laicidad genera un peligro potencial nacido de su propia lógica: los focos de resistencia que antes detectaban en las religiones se esconden ahora en grupos (étnicos, lingüísticos, nacionales...y también religiosos) que pueden actuar como alternativa tanto frente a las religiones tradicionales como frente al proyecto moderno de la laicidad.

d. El espacio dejado vacío por el Dios de las religiones y por la razón política de la laicidad queda ocupado por otros poderes o fantasmas impersonales que acaban dominando las sicologías de los ciudadanos. Cuando el espíritu trasgresor del siglo XX ha socavado los principios y valores se impone la fuerza del mercado que convierte al ciudadano en productor o en consumidor. La sensación de soledad o de impotencia hace brotar con más fuerza la necesidad de un afecto compensatorio, que orienta al individuo al grupo emocional o cálido (especialmente la familia).

e. Tras haber intentado marginar la religión tradicional en el mundo occidental se ha producido la irrupción de otras religiones, procedentes de otros contextos culturales, cuya asimilación produce tensiones y disfunciones inevitables. De modo especial resulta problemática la integración del Islam, por llevar consigo un modo de civilización muy alejado de los principios y valores de la laicidad. La propuesta cosmopolita y multicultural puede no ser más que un voluntarismo bienintencionado cuando el espíritu fundador de la laicidad ha perdido aliento e ilusión. 
¿Se encuentra la laicidad en condiciones de ofrecer respuestas y convicciones para superar esos fenómenos que surgen en el ámbito de la laicidad? Algunos -como reacción ante tales dudas- pretenden reafirmar la validez de los principios fundadores. Esta actitud se convierte sin embargo, en ideología vacía si no reconoce los vacíos que encierra y, sobre todo, los vacíos del ciudadano cuando no es más que ciudadano. Este reajuste puede llevar consigo un rebrote mal disimulado de actitudes anti-religiosas, una ocasión propicia para consumar la excomunión política de las religiones.

Con motivo de la polémica suscitada por el velo islámico (y de los fantasmas que lo acompañaban) el presidente Chirac volvió a proclamar la identidad francesa unida a la laicidad. En este contexto, y sobre este trasfondo, conviene valorar el sentido y el alcance de las palabras de Mons. J.P. Ricard, presidente de la Conferencia Episcopal Francesa:

Se ha hablado mucho en los últimos tiempos de laicidad en peligro. La dificultad es más fundamental. Lo que está en peligro... es la voluntad de vivir juntos y en solidaridad por parte de los franceses. Nos encontramos en una sociedad que magnifica al individuo, sus aspiraciones, sus deseos, sus proyectos... En esta perspectiva ¿qué solidaridad hay entre categorías profesionales diferentes? ¿Qué mezcla social en los barrios para evitar los guetos de poblaciones en determinados espacios urbanos?... Cuando disminuye la solidaridad, cuando se debilita la conciencia de una responsabilidad común, aparece la violencia... Para fundar esa solidaridad social y nacional se requieren valores simbólicos fuertes, una concepción del hombre y de las relaciones humanas compartidas por el mayor número posible. Sin estos valores, cada uno se retraería en su nicho, en la defensa de su ámbito, en el único horizonte de su grupo religioso. Reconozcamos que hay un déficit de referencias simbólicas en nuestra sociedad. La crisis de transmisión de valores que atraviesa nuestra sociedad no afecta sólo a las familias, a la escuela, a las iglesias. Roza el umbral de los valores fundadores de la República. Hay un desafío que es vital observar. No dejemos esa tarea sólo al Estado. Es responsabilidad de cada uno de los componentes de nuestra sociedad aportar su contribución a esta obra común.

Estas palabras expresan la voluntad de apoyar la laicidad en favor de la laicidad misma, sin voluntad de dominio ni de imposición (pues de hecho sería imposible). La Iglesia por ello debe reajustar su presencia y su mentalidad ante una tarea que debe compartir con otros protagonistas sociales. La teología tiene que ayudar al conjunto de los cristianos a superar la indiferencia o, lo que sería peor, a condenar de hecho la laicidad dando origen a uno más de los comunitarismos posibles. Por su propia vocación la Iglesia debe renunciar a toda tendencia sectaria, que es 
irresponsabilidad o foco de violencia.

El fomento de actitudes cívicas, de virtudes de ciudadanía, constituye una de las tareas del presente para habitar la Galilea de los gentiles, pues es un modo de evangelizar desde la presencia pública. Contribuir a la vida de la sociedad, al dinamismo social, es el mejor medio de frenar las pretensiones del Estado, consiguiendo que sean los protagonistas sociales los que generen actitudes y convicciones profundas. Ante esa posibilidad los cristianos no pueden recluirse en su propia comunidad o en su mundo, como denuncia de la catástrofe que amenaza la moral de la sociedad.

\section{La aportación de la propia inteligibilidad}

Con conciencia de responsabilidad, desde el apoyo realizado a los marginados o a los desfavorecidos, el protagonismo eclesial debe ser más decidido y comprometido, para afrontar la excomunión política que se ha lanzado contra las religiones. Ello se ha de realizar ciertamente desde la práctica del amor en lo concreto. Pero a la vez desplegando el lógos que la revelación le ha entregado, generando por eso tanto los valores simbólicos como el potencial de inteligibilidad que debe enriquecer la experiencia colectiva. Este es el terreno en el que la dignidad de creer se puede manifestar con mayor esplendor. Es la vía para afrontar la excomunión intelectual. Es el modo de hacer ver que la separación tajante entre lo justo y lo bueno es peligrosa por imposible. Esta será en adelante la gran tarea de la teología. A pesar de las incomprensiones.

La aportación de la Iglesia (y de las religiones en general) viene también avalada, y hasta esperada, por exponentes de la modernidad laica. Se podrán mencionar ( $y$ hay que hacerlo) las limitaciones de tal reconocimiento. Pero se trata de un reajuste notable de la actitud. La fe se ve invitada a desplegar la dignidad de su propia inteligibilidad. Conviene recordar, aunque sea brevemente, algunas de las voces más significativas.

El mismo Rawls llegó a reconocer la inviabilidad de una separación neta entre lo justo y lo bueno, por lo que reclamaba un acercamiento que hiciera posible la aportación de los creyentes en el debate público. A raíz de las críticas dirigidas contra su Teoría de la justicia 4 introduce la necesidad y conveniencia de un esfuerzo de overlapping de las distintas concepciones del mundo. Considerando racionales a todos los participantes en el diálogo social, hay que fomentar una neutralidad que facilite ese encuentro (aunque no sea más que un recubrimiento parcial) de los ciudadanos que no

4 J. Rawls, Teoría de la justicia, Fondo de Cultura Económica, 20066 
renuncian a sus creencias ni las ponen entre paréntesis.

En cierta medida resulta especialmente paradigmática la evolución de Habermas ${ }^{5}$, defensor convencido de los valores de la razón moderna, pero consciente igualmente de sus unilateralidades y estrechamientos. Si aspira a crear una razón intersubjetiva que se ejerza en situaciones ideales de diálogo, era de esperar que llegara a cuestionar la exclusión de las religiones en el mundo de lo mítico y preracional. Así lo sostenía en sus primeros escritos, cuando la razón secular parecía en condiciones de responder a todas las cuestiones humanas que tuvieran sentido. Progresivamente fue ampliando su perspectiva: hay cuestiones (como la muerte) que no pueden ser respondidas por la razón y que depositan en el espíritu humano una melancolía insuperable desde el horizonte secular; van surgiendo además cuestiones (especialmente a causa de las nuevas posibilidades técnicas) que requieren un juicio moral enraizado en el bien. Por ello solicita una colaboración de las religiones. Esta colaboración exige, por parte de la razón ilustrada, que no las condene como irracionales a nivel de principio; y exige de las religiones su disposición a traducir en contenido racional lo que han recibido de la revelación. El paso es muy importante: es lógico, desde su punto de vista, que no reconozca en las religiones contenidos cognoscitivos o informativos, pero ha llegado a admitir un componente semántico (o simbólico) del que la razón secular tiene necesidad.

Desde la perspectiva de la filosofía política J.M.Ferry ${ }^{6}$ se orienta en la misma dirección. La represión de los dos eventos teofánicos fundamentales, la noesis griega y la revelación judeo-cristiana, hizo surgir los sistemas totalitarios del siglo XX, como religiones políticas, sustitutivas del potencial semántico de la trascendencia perdida. Esa experiencia terrible ha curado al hombre europeo de la tentación de realizar políticamente las promesas soteriológicas. La opción liberal que entonces se impone corre el riesgo, sin embargo, de convertirse en pensamiento único que decreta la excomunión política contra las intuiciones morales, contra las concepciones antropológicas de base, contra los principios de raíz religiosa.

Ante los problemas que actualmente se plantean (reacciones identitarias y comunitaristas, afirmaciones nacionalistas, integración supranacional, ingeniería genética, sentimientos emocionales ante la pena de muerte o el racismo...) no parece suficiente el modelo liberal laicista, ni siquiera según

5 J. Habermas (1929) filósofo y teórico social alemán. Su obra principal es Teoría de la acción comunicativa, 2 vols. Taurus, 1987.

6 J.M. Ferry, La ética reconstructiva, Siglo de Hombre, Bogotá, 2001 
el modelo de overlapping ${ }^{7}$ de Rawls ${ }^{8}$. Hace falta reconocer la insuficiencia y la falsedad del prejuicio de una razón libre de presupuestos, la ineficacia de un procedimiento de diálogo sin confrontación o la ilusión de esperar una adhesión a la legalidad democrática sin valores antropológicos.

Se requiere por ello una ética reconstructiva que recoja las intuiciones profundas archivadas en el potencial semántico de las religiones (éticas, no políticas), que pongan al descubierto los motivos más profundos de las diversas posiciones, para que se confronten las propuestas de sentido y de este modo se supere la cerrazón nacionalista, la tentación del pensamiento único, y se haga posible la integración. En este escenario las religiones pueden recuperar lo mejor de su memoria histórica para abrirse al diálogo como interlocutores de pleno derecho, racionalizando sus convicciones y entrando en un proceso abierto de explicación y de justificación.

Este reconocimiento y esta aceptación se dirigen con más confianza (lo cual no deja de ser significativo) al cristianismo, porque muestra una mayor congruencia con los derechos humanos y con las grandes conquistas de la razón occidental. El diálogo se plantea no obstante, temiendo en cuanta algunas reglas de juego: La afirmación de los derechos humanos como más incluyentes que las religiones; el evitar todo acceso particular de principio a un bien sustancial; la justicia política es un principio más universal que el de las religiones; todos los dialogantes deben asumir una actitud falibilista y renunciar a reencantar el mundo o dar un alma a Europa: en el espacio público la Palabra de Dios no es más que la palabra de los hombres y mujeres que pretenden enunciarla; el valor de los procedimientos se mide por su capacidad para hacer compatibles entre sí los intereses individuales; las normas llamadas a regir la sociedad no se deben hacer derivar directamente de valores sustanciales...

Las reglas de juego que acabamos de enumerar suscitan, desde el punto de vista teológico, algunos interrogantes que recogeremos posteriormente. En cualquier caso se ha desplegado un espacio de encuentro y de diálogo en el que la teología debe ayudar a recrear la presencia cristiana en una sociedad y en una cultura que se identifican como modernas e ilustradas. Esta presencia cristiana es necesaria por los desafíos objetivos de la sociedad y por las exigencias de la subjetividad creyente, que debe salir al encuentro de todos en la diversidad de civilizaciones en que se han configurado. También, por tanto, de los habitantes de la civilización moderna e ilustrada, con la que -por otro lado- la une una sintonía

7 Del verbo inglés overlap: solaparse, superponerse, imbricarse.

8 John Rawls (1921-2002) Profdesor de filosofía política en la Universidad de Harvard es considerado como uno de los filósofos políticos más importantes del siglo XX. 
profunda. De su propio pozo la Iglesia ha de sacar un agua que acreciente la fecundidad de esa cultura. Esta contribución puede ser considerada en una doble perspectiva o en un doble nivel.

Por un lado, son la libertad y los derechos humanos, propugnados por la razón, las coordenadas de la mentalidad democrática y liberal. Desde el punto de vista teológico se percibe con claridad la concordancia entre los presupuestos modernos y los cristianos. Además, desde su particularidad, la religión cristiana amplía y profundiza los presupuestos de la razón: el individuo debe ser considerado como persona; la persona es apertura y comunicación; la revelación habla de una capacidad de amar que lleva consigo el reconocimiento del diferente y la defensa del pobre y desvalido; la universalidad de la razón que llega a hablar de fraternidad entre todos los seres humanos es avalada por la referencia a un Dios creador y a un Cristo redentor; la dignidad del ser humano que lleva en sí la imagen de Dios constituye una invitación al diálogo o a la denuncia profética cuando sean mancillados los derechos de los más vulnerables... El lógos de la razón moderna y el lógos de la fe se encuentran en un contenido semántico compartido. Por tanto la fe aporta alma y corazón para adherirse a los pilares sobre los que se levanta la laicidad.

Por otro lado, en el diálogo y la comunicación la teología puede desplegar una inteligibilidad que enriquece la razón porque la desborda, de modo tal que el desbordamiento no pueda ser considerado como amenaza o imposición heterónoma. Esta es la tarea más urgente para mostrar la dignidad de la fe por vías insospechadas para la razón crítica y emancipada. El lógos particular de la fe encuentra ahí un camino para acceder a una universalidad que no puede alcanzar la razón meramente natural. Es lo que puede conseguir que la religión no sea vista como cumplimiento de ritos o de prácticas rituales o de esquemas morales. Para romper esos prejuicios cuenta con el lógos de la revelación y con la realización existencial por parte de muchos creyentes que encarnan un modelo antropológico alternativo y que deben mostrarlo como alternativa a la lógica social dominante.

Para explicitar lo que acabamos de decir pueden bastar dos ejemplos significativos. En primer lugar, el amor al enemigo, como singularidad prototípica del Evangelio. El amor al enemigo no brota espontáneamente de las tendencias naturales ni se deduce automáticamente de la claridad de la razón. Por eso encuentra tan difícil acogida en la filosofía moral o en la ética autónoma. Desde el punto de vista cristiano se puede proponer la realización que encontró en la vida de Jesús y, por ello, la transformación en la imagen de Dios y en la imagen del ser humano (pues corresponde con la voluntad de Dios el amor al ser humano en su enemistad o en su odio). Ante el desconcierto de la razón la teología tiene que lanzar su 
pregunta: ¿no es más digno del ser humano ser capaz de amar hasta tal extremo?, ¿no sería mejor el mundo en el caso de que se extendiera como modo de situarse en la realidad y ante los otros?, ¿no ha de servir como criterio ideal para guiar los comportamientos humanos? Nos encontramos aquí con un contenido semántico que va más allá de la razón, que enriquece nuestra experiencia de humanidad y que por ello puede fecundar la convivencia y las relaciones sociales.

En segundo lugar, el sentido y el valor de la cruz. Tanto por los modernos como por los postmodernos el Crucificado es considerado como lo más opuesto a Prometeo y a Dionisio. La cruz sin embargo, no es la negación de la vida ni de la razón, sino una condición de posibilidad: la razón debe pasar a través del calvario de la realidad y el corazón amante ha de pasar a través del rechazo y de la oposición. Porque la cruz no es un concepto abstracto que se refiera a un Dios cruel sino que es la condensación de la historia humana de la crueldad que va dejando permanentemente víctimas. Quien ha sido capaz de afrontar la cruz sin deseos de venganza está en condiciones de acercarse a los crucificados para reivindicar su dignidad sin caer por ello en los círculos diabólicos de la amargura y de la violencia. Hablar de la cruz no es un signo de masoquismo sino una expresión de la realidad del ser humano en su grandeza y en su miseria. ¿No esconde un lógos que debe ser escuchado por la razón universal autosuficiente y formal?, ¿no quedaría olvidada la dignidad de los vencidos en el caso de que la cruz no penetre en la mirada de la razón?, ¿no son los crucificados los que deben reclamar sensibilidad (y emoción hasta el compromiso) a la razón que se clausura en la distancia de los principios o de los procedimientos?

\section{El laicismo y la seducción pagana}

En los autores mencionados anteriormente se expresa el reconocimiento de la aportación de las religiones; incluso se llega a valorar su aportación semántica, aunque le nieguen capacidad informativa o cognoscitiva. No obstante sigue siendo la razón laica la que establece las reglas de juego y la que señala el escenario del diálogo, la que actúa como juez y como árbitro, a pesar de sus insuficiencias y carencias. Se insinúa de nuevo la dificultad que tiene ese tipo de razón para confrontarse con lo realmente distinto de sí misma.

En cualquier caso esas actitudes se mueven en el espacio de la laicidad, del intento de crear un espacio de diálogo para protagonistas diferentes. Por ello es más fácil de percibir el paso al laicismo: cuando se impone la tentación de la excomunión (del ámbito de la política y de la racionalidad) 
dirigida contra las religiones, aunque expresamente se proclame la renuncia a la hostilidad.

Un ejemplo típico de esta actitud la ofrece Pena Ruiz ${ }^{9}$ : su defensa de la laicidad le lleva a considerarla como condición de posibilidad trascendental de la vida social. Niega que la laicidad sea una opción espiritual particular, pues se arroga un nivel de universalidad frente a las posiciones diferenciadoras y comunitaristas. Esa universalidad es un principio superior que no necesita ser matizado como laicidad plural, abierta, positiva o deliberativa. No necesita de ningún otro principio de legitimación, de justificación o de contrapeso. Es la única garantía de libertad, de neutralidad, de igualdad y de democracia. La laicidad es la afirmación originaria del pueblo como unión de hombres iguales y libres. Suyo es por tanto, el espacio público. Ninguna otra concepción espiritual debe gozar por tanto, de reconocimiento o de ventajas materiales o simbólicas. Sólo en cuanto asociaciones de derecho privado podrán adquirir dimensión colectiva.

Como la laicidad se atribuye (monopoliza, podríamos decir) el espíritu de concordia, cualquier concesión a las religiones en cuanto religiones introduciría un privilegio que genera discriminación entre los ciudadanos que deben ser iguales. La violencia, de modo implícito y explícito, es vinculada a las religiones, concretamente a las tres grandes religiones del Libro. El clericalismo es la figura que adoptan las religiones cuando pretende influir en el debate público a través de autoridades que se arrogan capacidades que no están legitimadas ni racional ni jurídicamente. Ese clericalismo debe ser cortado de raíz porque sería la contradicción de la laicidad.

Las convicciones particulares pueden ejercer influencia social por la vía de la libre expresión en el debate público. Ahora bien, es el individuo el único sujeto de derecho, no las Iglesias o comunidades religiosas en cuanto tales. Ese individuo se puede mover en el horizonte laico desde el pensamiento liberado de toda tutela (de todo clericalismo), susceptible por ello de abrirse a lo universal. Así queda desactivada toda violencia expresa o larvada. Y así se distinguen con claridad la esfera pública y la privada, los criterios sobre el bien y los consensos sobre lo justo.

Esta opción laica, frente a lo que le reprochan sus críticos, se presenta como lo contrario del relativismo o de la indiferencia ante los valores. La

9 Henri Pena Ruiz, Doctor y catedrático de Filosofía en la Escuela de Estudios Políticos de París. Varios libros sobre laicidad, destacamos, La emancipación laica. Filosofía de la laicidad. Ed. Laberinto, Madrid, 2001. 
universalidad y la autonomía establecen en el ámbito público una exigencia de razón y de verdad, y ofrecen a los individuos una fuerza a la que adherirse. El estado en consecuencia no necesita ninguna legitimación externa o superior ni reclama una transferencia de sacralidad ni instaura una religión secular. Es la propuesta de un humanismo, distinto del tradicional, que no se basa simplemente en el conformismo o en el consenso sino en la universalidad auténtica, en la búsqueda razonada de lo universal. La laicidad, en esta perspectiva, propone un ideal cuya comprensión en el orden del derecho se basta a sí mismo como garantía de paz social y de convivencia.

Esta postura se sitúa en el plano explícitamente político. Pero hunde sus raíces en concepciones ideológicas de mayor calado filosófico. A un nivel se puede hablar de excomunión política. A otro nivel se puede tratar de excomunión del ámbito de la racionalidad. En tal caso resultaría difícil distinguir la tolerancia de la hostilidad. Sería superficial, desde el punto de vista teológico, reducirse a considerar el nivel estrictamente político o de filosofía política. Sólo desplegando sus presupuestos o implicaciones se puede captar la gravedad y la trascendencia del desafío y de la respuesta requerida.

La raíz más profunda brota de una dinámica inserta en la llustración y en la razón autónoma que condena por principio la posibilidad de una revelación positiva protagonizada por un Dios personal. El integrismo de la laicidad (R. Rémond) se levanta cuando percibe o intuye frente a sí a lo auténticamente otro o distinto, que quiebra la pretensión absoluta de la autonomía humana. Por ello la Iglesia se convierte por definición en la figura maldita de la Ilustración, la infame que debe ser destruida y que por ello no puede ser tolerada, ya que vive de una palabra o de una voz pronunciada por Alguien que habita en un nivel de realidad que no es controlable por la razón.

El pensamiento moderno ha estado atravesado permanentemente por esta dialéctica entre la autoafirmación y la conciencia de sus limitaciones, sin que se haya logrado el equilibrio adecuado: por un lado la razón se considera como lo único universal y necesario, que por ello condena como insignificante lo histórico y lo contingente, a lo cual niega toda pretensión de universalidad o de enriquecimiento de la razón (es la duradera cuestión sobre la religión positiva frente a la religión natural); por otro lado es consciente de la insatisfacción o vaciedad cuando queda reducida a algo formal que no espera más novedad que el despliegue de lo que ya implícitamente posee o que reprime las dimensiones antropológicas que no son estrictamente racionales o racionalizables. Intentos como los de Hegel o Schelling (como contrapunto a las divisiones abiertas por Kant) buscan un equilibrio o una compensación o un tipo de razón que supere esos focos de tensión y de escisiones: aportar un contenido a la llustración 
insatisfecha o incorporar un componente positivo a la filosofía negativa de la razón. Es lo que, recurriendo a vías múltiples, pretendía el romanticismo: superar la escisión de la experiencia humana y recuperar lo reprimido por la razón absoluta e intolerante.

En todos estos intentos sin embargo, a pesar de su aliento positivo, sigue funcionando en la mayoría de los casos la aspiración de la razón a convertirse en la juez única que discierne o legitima lo que tiene derecho a existir y a ser reconocido como racional. Abandonada a sí misma o, dicho de otro modo, asentada en su prepotencia, la razón corre el riesgo de cerrar la experiencia humana y la anchura y profundidad de la realidad en el marco de las paredes del mundo. Es la tentación, en palabras de Lévinas (que prolonga perspectivas de Rosenzweig), del paganismo: la impotencia radical de salir del mundo, la incapacidad radical de transgredir los límites del mundo. El paganismo, así entendido, no consiste en negar la existencia de dioses o de espíritus, sino en la figura de un yo colocado en el centro de la propia existencia sin el contrapeso que podría aportarle la relación a una instancia que sea tal por su inconmesurable exterioridad.

La Iglesia, en cuanto producto -y a la vez portavoz- de una revelación que introduce una fisura en las paredes del mundo, es por definición fanatismo, fundamentalismo, generadora de divisiones y de violencia. Lo que está en cuestión (por lo que es criticada, acusada o condenada) no es por tanto, la inmoralidad o antitestimonio de la Iglesia realmente existente, sino la idea misma de Iglesia. La idea de Iglesia se ve llevada al banquillo de los acusados no sólo por los dinamismos políticos señalados sino por la pretensión más profunda y más amplia de un tipo de razón que pretende imponerse en todos los ámbitos de la realidad, también en la misma teología.

Esta lógica se puede percibir en algunos campos del actual debate teológico: surgido éste como reivindicación de verdades olvidadas o de actitudes descuidadas, puede acabar ahogado por las pretensiones inacabables de esa figura de la razón que también empuja desde la laicidad hacia el laicismo: Como ejemplo, se pueden recordar algunas orientaciones: la teología pluralista de las religiones cuando pretende imponer a todos los fenómenos religiosos una noción de religión elaborada por la razón; el soteriocentrismo práxico cuando prescinde de la referencia a la identidad de Jesús o de Dios para definir lo que significa irredención; la teología feminista cuando avanza hacia posiciones postcristianas para eludir la exigencia de la positividad cristiana... Como se ve, la teología se encuentra con un abanico de cuestiones que en último término viven de la misma dinámica de una razón que reduce la alteridad o la exterioridad. 


\section{La fe como lógos}

En este escenario, cuando se ha desplegado el fondo del problema y lo que está en juego, la actitud a adoptar se debe situar en una doble coordenada: la crítica ante pretensiones desmesuradas por instancias humanas y mundanas, y la reivindicación de la propia universalidad por parte de la Iglesia y de lo que ella representa.

La primera coordenada que hemos señalado exige por parte del pensamiento cristiano denunciar el peligro de que el puesto de Dios quede ocupado o absorbido por el estado, lo cual lleva consigo la idolatría (estatolatría) y a la reducción del ser humano a una sola de sus dimensiones.

\subsection{El Estado se sitúa en una posición ambigua o ambivalente que puede acabar en inconsciencia o en hipocresía.}

El Estado laico propugna una estricta neutralidad, justificada en su pretendida incompetencia en temas religiosos. Esta incompetencia sería la garantía de la libertad de todos los ciudadanos. No obstante, al menos de hecho establece lo que es religión, incluso determinando que no puede moverse más que en el ámbito privado. Apela a la separación entre lo justo y lo bueno pero sin reconocer que esa distinción exige una serie de criterios que viven de una antropología y de la ética, de la fijación de lo que es lo mejor y lo peor. ¿No considera como algo bueno que el individuo sea libre e independiente?, ¿es ello posible sin los presupuestos cristianos de una civilización particular?

Esta aporía no oculta una concepción del mundo que, aún pretendiéndose post-metafísica, es una auténtica metafísica ya que establece lo que es la realidad y las vías para acceder a ella. Es significativo que la reivindicación de la laicidad lleva consigo la tendencia a estatalizar los procesos educativos. Síntoma claro es que en el campo de la escuela es donde se han planteado las polémicas más fuertes y donde se ha hecho necesaria una sabiduría que permita conjugar los intereses de los diversos actores sociales y la defensa de los distintos derechos. No se pueden negar los acuerdos logrados en este campo, pero tampoco se debe ocultar que la razón que se pretende pura y neutral por universal está movida por intereses ideológicos que también son particulares. Por eso hay que denunciar los riesgos de sacralizar el estado o la república para que no se sitúen a un nivel absoluto equivalente al que se niega a Dios: ¿no está exigido en justicia hacerse razonable ante quienes piensan de modo distinto?, ¿con qué derecho se atribuye una catolicidad que puede ser violenta al negar su propio carácter de particularidad? 


\subsection{La ideología laicista lleva consigo una antropología}

Es decir, una concepción del hombre, que de hecho establece una división entre lo religioso y lo profano, entre lo privado y lo público que inevitablemente introduce un elemento de esquizofrenia en la existencia concreta. Tal planteamiento pretende además algo imposible: ningún sujeto puede prescindir de sus convicciones cuando actúa como ciudadano. Bajo una pretendida una universalidad se reduce al ser humano a mero individuo, dado que sólo el individuo es sujeto de derechos. Con lo cual se lesionaría la dimensión social del ciudadano, que también se expresa en la dimensión religiosa.

El ciudadano es secuestrado de la realidad de la vida social. Pues éste muestra una constante dificultad (que tal vez sea imposibilidad) para separar lo religioso de lo público. El hecho de la sucesión ininterrumpida de problemas ¿no hace ver que el laicismo aspira a un ideal imposible e inviable, que por ello ejerce violencia sobre la realidad y sobre los seres humanos concretos?, ¿se sienten éstos realmente respectados cuando no se les escucha en lo que les da razones para vivir?, ¿no ganarían la racionalidad del estado y la de los individuos en el caso de que ese encuentro fuera posible?

La segunda coordenada que mencionábamos plantea a la Iglesia y a la revelación la pregunta decisiva: ¿pueden éstas reconocerse como una particularidad que, en consecuencia, se encuentra a un nivel inferior a la universalidad que es propia de la razón? Esta pregunta nos confronta con la cuestión de la inculturación en una sociedad en la que la razón se ha afirmado como la instancia superior.

La situación actual recuerda la situación que debió afrontar el lógos cristiano en el siglo II por medio de los (llamados) Padres Apologistas. También en aquel momento un grupo social minoritario, la Iglesia, iniciaba su protagonismo histórico en el seno de una civilización segura de sí misma, apoyada en la estructura imperial romana y en la tradición filosófica griega. A su modo también el helenismo se sentía ecuménico, es decir, globalizado. ¿Debía la Iglesia reconocerse como un elemento particular ante un lógos que la juzgaba y la legitimaba? Ya en aquel momento se abre un abanico de posturas, pues es de esperar que no todos encuentran las mismas respuestas: hay quien se opone a la cultura cerrándose en el propio grupo (Taciano), hay quien se siente indiferente ante la cuestión de fondo (Teófilo), hay quien tantea soluciones o vías de integración (Justino), hay quien piensa normalmente su fe en la atmósfera cultural (Atenágoras), hay quien vive armoniosamente su pertenencia al mundo griego y al mundo cristiano (Clemente de Alejandría)...

Visto en perspectiva histórica, el desarrollo cristiano fue posible porque 
pensó la fe desde la luminosidad del lógos griego y porque afirmó sin complejos que el Lógos (de impronta platónica o estoica) se había hecho carne, que el hombre Jesús era la encarnación del Lógos universal. Como muestra el ejemplo de Atenágoras, que reconoce la autoridad imperial y ante ella defiende la propia dignidad. Pero, más allá del condicionamiento político, la osadía intelectual consistió en evitar a la vez el complejo de inferioridad y el complejo de apocalipsis: viviendo con pasión su momento histórico, aportando la fe en un Dios único y personal, la esperanza de un futuro que es más amplio que el escenario histórico, un amor que se ofrecía a todos y especialmente a los desheredados.

De modo análogo a la empresa realizada por los Padres Apologistas la teología debe redescubrir toda la fuerza de la inteligibilidad que se encuentra en el hecho cristiano, liberándose de la presión que ejercen sobre ella las filosofías que pretenden monopolizar el lógos de la realidad y de la subjetividad humana. El acontecimiento cristiano (la revelación, la encarnación y el misterio pascual) permite desplegar unas posibilidades propias. Documentos papales como Fides et Ratio o Deus caritas est han ofrecido puntos de referencia y realizaciones concretas. La pregunta por la verdad desde el punto de vista cristiano permite configurar un pensamiento que salga al encuentro de las nostalgias o de las resignaciones del pensamiento post-metafísico y también de la vieja filosofía (el nuevo pensamiento, alimentado de la savia judía aporta perspectivas ineludibles para hacer comprender que la revelación es nacimiento de la razón).

El pensamiento cristiano, concebido como auténtico proyecto cultural, ha de ofrecer a los cristianos un hogar intelectual en el que puedan encontrar el sentido de la realidad, pues en caso contrario tendrán que experimentar la desagradable sensación del desierto o la tentación de buscar las respuestas en otros ámbitos ideológicos. ¿Por qué sólo en el servicio de la caridad ha de pronunciar su palabra callada la acción de los cristianos? ¿No es éste el tiempo privilegiado para seguir trabajando la palabra del lógos que brota de los contenidos más genuinos de la fe cristiana? En tiempos más recientes ofrecen un ejemplo y un modelo la escuela de Tubinga (en la difícil transición entre el Antiguo Régimen y el racionalismo prepotente) o intentos como el de Romano Guardini que acompañaba el despertar de la Iglesia en las almas con una interpretación de los monumentos culturales de nuestra herencia en aquella crisis que desembocaría en los totalitarismos políticos. Nuestra experiencia histórica está clamando por propuestas equiparables a las mencionadas.

A la vez que se edifica el hogar intelectual para el pueblo cristiano hay presupuestos para elaborar una filosofía primera que transfigure la mirada sobre la realidad haciendo ver que en el origen se encuentra un Lógos amante o un Amar originario que sostiene la dignidad de la persona y la 
bondad de lo que existe. La donación como dato originario permite conjugar el valor de lo individual con la perspectiva universal de la razón, que puede ver su verdadero nacimiento en la revelación $(\mathrm{H}$. Cohen), precisamente porque de ella se recibe la luz que permite captar el resplandor de todo lo que existe.

Esta razón, que vive de una donación originaria y de un amor que todo lo abraza, no puede desvincularse del respeto de la pluralidad de las diferencias. El verdadero pensamiento -como el cristiano- no puede ser ni homogeneizador ni creador de enfrentamientos. Por eso el pensamiento a la luz de la revelación ha de ser integrador y católico. La razón que brota de la revelación no puede caer en el formalismo o en la vaciedad de lo procedimental. Ha de dar origen a una civilización, incluso a un régimen político en el sentido más noble de la palabra, es decir, la configuración de una convivencia humana que pueda servir como propuesta en el mundo de la globalización: por un lado, en la voluntad de hospitalidad hacia los venidos de fuera; por otro lado, gracias al desarrollo efectivo de la catolicidad de la Iglesia como comunión de iglesias que muestre, precisamente en este mundo, la integración de lo universal y de las diferencias (la fe cristiana debe hacerse también civilización).

Legitimada filosóficamente y realizada prácticamente, la teología ha de actuar con la paciencia que exige la complejidad de la historia y los intereses de los seres humanos. La teología de amplio respiro no puede confundir la osadía de su alternativa con la confrontación directa a nivel de intereses humanos. Ante todo, porque vive de la revelación procedente de un Amor entregado que no reacciona nunca con odio y con venganza, pues sabe que su don es oferta que debe avanzar con prudencia hasta el umbral de la libertad humana. Además, porque el pensamiento es humano, ejercido por personas finitas, y que por ello debe pasar a través de los inacabables (pero necesarios) esfuerzos de la hermenéutica, del diálogo, de la inculturación. Como advertía Rosenzweig a los judíos de su época: Diferencia sí, separación no; queremos un hogar, no un gueto.

Los principios son criterios y fuentes de inspiración, no el recurso permanente de afirmaciones tajantes, que olvidan el esfuerzo del concepto y la complejidad de lo real. El lógos (y el Lógos) es diá-logo, y por ello debemos aprender a ejercerlo como diálogo de salvación que encuentra a los destinatarios con la imagen del Evangelio que hace vivir a la razón. El escenario histórico y las fuentes de la revelación llaman a la vez a la Iglesia a superar el complejo de inferioridad y el complejo de apocalipsis porque tiene una dignidad que vive de la alegría pascual y que por ello la empuja a recorrer los intrincados caminos de la historia real. 